\title{
Potential Prebiotic and Anti-obesity Effects of Polysaccharides from Codium fragile
}

\author{
Suwon Oh ${ }^{1,3}$, Sungkeun Kim ${ }^{2}$, Kyoojin Jung ${ }^{1}$, Thi Ngoc Anh Pham ${ }^{3}$, Seungwhan Yang ${ }^{3, *}$ and Byungjae Ahn 1,* \\ 1 Marine Biotechnology Research Center, Jeonnam Bioindustry Foundation, 21-7, Nonggongdanji 4Gil, \\ Wando-eup, Wando-gun, Jeollanam-do 59108, Korea; swoh@jbf.kr (S.O.); kjjung@jbf.kr (K.J.) \\ 2 Bada and Haecho Fishery Crorp., 1111-2, Cheonma-ro, Pungyang-myeon, Goheung-gun, Jeollanam-do \\ 59548, Korea; wnbagirl@naver.com (S.K.) \\ 3 Department of Biotechnology, Chonnam National University, Yeosu 59626, Korea; 197621@jnu.ac.kr \\ (P.T.N.A.) \\ * Correspondence: ymichigan@jnu.ac.kr (S.Y.); bjahn@jbf.kr (B.A.); Tel.: +82-61-659-7306 (S.Y.); \\ $+82-61-550-1720$ (B.A.)
}

\begin{abstract}
Polysaccharides from marine algae exhibit beneficial biological activities. In this study, we examined the effect of polysaccharides from Codium fragile (PCF) on prebiotic and anti-obesity activity. PCF increases the growth of specific beneficial microbial populations with concomitant decrease in pathogenic microbes. Further, total phenolic content (TPC), total flavonoid content (TFC), and DPPH radical scavenging activity (DPPH activity) after fermentation with PCF as carbon source were higher than for the glucose as control. Moreover, PCF inhibited adipocyte differentiation by inducing differentiation-related factors when the induction of 3T3-L1 preadipocytes into adipocytes was induced. Therefore, we suggest that PCF can be used as prebiotic material with anti-obesity for human health.
\end{abstract}

Keywords: Codium fragile; marine algae; anti-obesity; prebiotics

\section{Introduction}

Marine algae are important sources of compounds with health-enhancing biological properties [1], including anti-inflammatory, anti-cancer, and immune enhancing functionalities [2-5]. Marine algae contain large amounts of sulfated polysaccharides that can be used as prebiotics [6]. These polysaccharides are structurally atypical compared to terrestrial glycans and are resistance to gastric acid, gastrointestinal absorption and host digestive enzymes [7]. Marine algae polysaccharides can be used as prebiotics for gut microbiota, which partially degrade them into other bioactive compounds, such as oligosaccharides and short chain fatty acids (SCFAs) - acting as food sources for these organisms and allowing them to proliferate [8-12]. In addition to these polysaccharides, marine algae contain other bioactive compounds, such as polypeptides, polyphenols, and phytochemicals, which can be used as prebiotics. Despite their myriad of biologically active compounds, marine algae are predominantly consumed as food, processed with salt or seasoning. There is therefore scope for expanding the development of functional foods which contain various bioactive compounds derived from marine algae.

Codium fragile is a green algae used as a traditional food ingredient in Asia [13]. Green algae produce high amounts of sulfated polysaccharides including sulfated galactans, mannans, xylans, and ulvans. These sulfated polysaccharides are composed of galactose, rhamnose, xylose, glucose, glucuronic acid and sulfates (and more rarely, mannose and arabinose) [6, 14]. Sulfated polysaccharides derived from green algae have shown various biological activities, including anti-viral, immune-stimulatory, and anti-cancer effects [15-17].

Obesity is a disorder involving excessive body fat which increases the risk of many diseases, including diabetes, high blood pressure, and other cardiovascular complica- 
tions. Marine algae consumption is associated with an anti-obesity activity affected by various mechanisms including alterations of lipid metabolism, inhibition of inflammation, suppression of adipocyte differentiation and delay in gastric emptying [5]. The anti-obesity activity of marine algae is associated with bioactive compounds, including polysaccharides, peptides, phlorotannins, and carotenoids [18]. Fucoxanthin is the most well studied marine algae bioactive compound displaying an anti-obesity effect [19]. Phlorotannin has been shown to strongly inhibit lipid accumulation in 3T3-L1 adipocytes [20], as well as inhibit adipocyte differentiation. Fucosterol has been reported to decrease the expression level of the adipocyte marker proteins PPAR and C/EBP. Marine algae may also prevent obesity by modifying relative amounts of different gut bacteria and polysaccharides from marine algae have been shown to repair the intestinal barrier and reduce inflammation [21].

In this study, we hypothesized that polysaccharides from C. fragile (PCF) are fermentation substrates for gut microbial populations which convert the PCFs into partially degraded bioactive compounds. A recent study showed that freeze dried C. fragile powder extracted with ethanol increase the abundance of SCFAs-producing bacteria, leading to an anti-obesity effect in mice [10]. Here, we performed in vitro evaluation of potential prebiotic and anti-obesity effects of PCF extracted with water.

\section{Materials and Methods}

\subsection{Preparation of $P C F$}

C. fragile was obtained from a seaweed farm in Wando, Jellanamdo, South Korea in September 2020. After removing salt by washing $C$. fragile sample with distilled water for $10 \mathrm{~min}$, the sample was dried at $47.5 \pm 2.5^{\circ} \mathrm{C}$ for $6 \mathrm{~h}$. The dried C. fragile sample was ground to a powder. After passing through a 20-mesh, samples were extracted using 20 times the amount of distilled water at $100^{\circ} \mathrm{C}$ for $3 \mathrm{~h}$. Then, PCF was concentrated using a vacuum rotary evaporator, freeze-dried and stored at $-20^{\circ} \mathrm{C}$ for later use.

\subsection{Chemical Composition of PCF}

The sugar content of the PCF was determined using the phenol-sulphuric acid colorimetric assay [22]. The uronic acid content was quantified by the methods described by Cesaretti, Luppi et al. [23]. The sulfate level was determined by hydrolyzing PCF with $1 \mathrm{M} \mathrm{HCl}$ for $12 \mathrm{~h}$ at $105{ }^{\circ} \mathrm{C}$, followed by performing the Dodgson-Price assay [24]. The monosaccharide composition was determined using high-performance anion exchange chromatography (HP-AEC). A Dionex ${ }^{\mathrm{TM}}$ CarboPac $^{\mathrm{TM}}$ PA1 column $(0.4 \times 25 \mathrm{~cm}$ : Dionex Co., USA) was used on a Dionex ${ }^{\mathrm{TM}}$ ICS-5000 (Dionex Co., USA) for this analysis. The injection volume was $10 \mu \mathrm{L}$ with a flow rate of $1.0 \mathrm{~mL} / \mathrm{min}$ at $25^{\circ} \mathrm{C}$. The mobile phase was $18 \mathrm{mM} \mathrm{NaOH}$ in water.

\subsection{Utilization of PCF by individual bacteria species}

Bacterial strains were obtained from American Type Culture Collection (ATCC, Manassas, USA) or from the Korean Collection for Type Cultures (KCTC, Daejeon, Korea). Evaluation of the growth of bacterial strains using PCF as a carbon source was performed according to a previously described method [25]. Briefly, each bacterial strain was grown separately in sugar-free brain heart infusion broth (BHI) containing $1 \%$ PCF. Glucose and galacto-oligosaccharide were used as controls [26]. Each bacterial strain was incubated for $24 \mathrm{~h}$. The growth of each bacterial strain was determined by measuring the optical density at $600 \mathrm{~nm}\left(\mathrm{OD}_{600}\right)$. Cells were harvested by centrifugation at $8,000 \times g$ for $10 \mathrm{~min}$ and diluted in phosphate-buffered saline (PBS) to an optical density (OD600) of approximately 0.5 before $0.2 \%$ was transferred for fermentation. After $24 \mathrm{~h}$ of incubation 
at $37^{\circ} \mathrm{C}$, OD 600 readings were taken using an ELISA reader (BioTek Instruments, Winooski, VT, USA).

\subsection{Stimulation of Probiotics Growth}

Two probiotic strains, Lactobacillus plantarum subsp. plantarum $(L p)$ and Lactobacillus helveticus ( $L h$ ) and were cultured in MRS broth, centrifuged and diluted in PBS to an optical density $\left(\mathrm{OD}_{600}\right)$ of approximately $0.5 .0 .2 \%$ of the culture of each probiotic strain was added in MRS broth containing 1\% PCF. Glucose was used as a control. Fermentations were monitored for $48 \mathrm{~h}$ at $37^{\circ} \mathrm{C}$, sampling every $8 \mathrm{~h}$ to determine the $\mathrm{pH}$, acidity, and viable cell count of $L p$ and $L h$. The $\mathrm{pH}$ was determined using $\mathrm{pH}$ meter (S20, Mettler Toredo, Switzerland). The acidity was determined by measuring the amount of $0.1 \mathrm{~N}$ $\mathrm{NaOH}$ required to adjust the $\mathrm{pH}$ to 8.2. The viable cells count of $L p$ and $L h$ were determined by counting the colony forming units (CFU) after plating on MRS agar and incubating under aerobic condition at $37^{\circ} \mathrm{C}$ for $48 \mathrm{~h}$.

Additionally, the SCFAs content, total phenolic content (TPC), total flavonoid content (TFC), and radical scavenging activity (as determined by a DPPH assay) were determined before and after fermentation. The SCFAs were determined using HPLC analysis. Two shim-pack SCR-102H $(300 \times 8.0 \mathrm{~mm}$, Shimadzu $)$ were used in series together with a shim-pack guard column SCR-102H $(50 \times 6.0 \mathrm{~mm}$, Shimadzu) on the HPLC system (Shimadzu, Japan). The injection volume was $20 \mu \mathrm{L}$ with a flow rate of $0.8 \mathrm{~mL} / \mathrm{min}$ at 40 ${ }^{\circ} \mathrm{C}$. The mobile phase was $4 \mathrm{mM} \rho$-toluenesulfonic acid in water. TPC was determined according to the Folin-Ciocalteu procedure [27]. Briefly, samples $(200 \mu \mathrm{L})$ were mixed with $2 \% \mathrm{Na}_{2} \mathrm{CO}_{3}(2.0 \mathrm{~mL})$ and Folin-Ciocalteu's reagent $(200 \mu \mathrm{L})$. After $15 \mathrm{~min}$, the absorbance values at $750 \mathrm{~nm}$ were measured using a microplate reader. Gallic acid was used as a standard and TPC was expressed as mg of gallic acid equivalents (GAE)/g of the fermented broth. TFC was estimated using the protocol established by Chang et al. [28]. Briefly, $150 \mu \mathrm{L}$ of each fermented broth sample was mixed with $280 \mu \mathrm{L}$ of de-ionized water, $10 \mu \mathrm{L}$ of $10 \%$ aluminum chloride, and $10 \mu \mathrm{L}$ of $1 \mathrm{M}$ potassium acetate. After incubation for $30 \mathrm{~min}$, the absorbance at $420 \mathrm{~nm}$ was measured using a microplate reader. The TFC content was presented as $\mathrm{mg}$ of quercetin equivalents (QAE)/g of the fermented broth. The radical scavenging activity of the fermented broth was determined using a DPPH assay [29]. Briefly, the fermented broth was prepared with different concentrations diluted with methanol. A mixture of $20 \mu \mathrm{L}$ sample and $200 \mu \mathrm{L}$ of $0.1 \mathrm{mM}$ DPPH - methanol solution was taken and incubated in the dark for $30 \mathrm{~min}$. The absorbance at $517 \mathrm{~nm}$ was measured. The fermented broth was replaced with methanol to serve as the blank control, and ascorbic acid was used as a positive control.

\subsection{Cell Viability}

The 3T3 - L1 cells were seeded at $5 \times 10^{3}$ per well in 96 - well plates in culture medium. Cells were incubated with PCF $(0.5-6 \mathrm{mg} / \mathrm{mL})$ for $24 \mathrm{~h}$ at $37^{\circ} \mathrm{C}$ in a humidified $5 \%$ $\mathrm{CO}_{2}$ atmosphere. The $5 \mathrm{mg} / \mathrm{mL}$ of MTT solution was added to each well followed by incubation for $2 \mathrm{~h}$. The medium was removed. $0.1 \mathrm{~mL}$ of buffered dimethyl sulfoxide was added to each well, and the plate was shaken to dissolve the formazan. Absorbance at 540 was measured.

\subsection{Oil Red O staining assay}

An Oil Red O staining assay was used according to the method described by Lee et al. [30]. Briefly, the 3T3-L1 preadipocytes were seeded at $5 \times 10^{5}$ cells $/ \mathrm{mL}$ in a 24 -well plate and adipocyte differentiation was induced by treatment with PCF $(1,2$, and 4 $\mathrm{mg} / \mathrm{mL}$ ). N-Acetyl-cysteine (NAC; $5 \mathrm{mM}$ ) was used as a positive control. 3T3 - L1 cells were fixed with $3.7 \%$ formaldehyde for $30 \mathrm{~min}$ and washed with PBS and ethanol. The cells were then stained with Oil Red O in isopropyl alcohol/distilled water for $30 \mathrm{~min}$ and washed with PBS and ethanol. Lipid droplets were observed with a Eclipse TE2000- 
U microscope (Nikon, Tokyo, Japan) and dissolved in isopropyl alcohol containing 4\% Nonidet $^{\mathrm{TM}} \mathrm{P}$ - 40 (Sigma - Aldrich) before quantification with a microplate reader (SpectraMax 190PC; Molecular Devices, Sunnyvale, CA, USA) at $510 \mathrm{~nm}$.

\subsection{Western Blotting}

Western Blotting was determined using the methods described by Lee et al. [30]. The 3T3-L1 preadipocytes were seeded at $5 \times 10^{5}$ cells $/ \mathrm{mL}$ in a 24 -well plate and adipocyte differentiation was induced by treatment with PCF (1, 2, and $4 \mathrm{mg} / \mathrm{mL})$. 3T3 - L1 cells were lysed whilst keeping on ice for $30 \mathrm{~min}$ in RIPA lysis buffer (ForBioKorea, Korea) containing a protease inhibitor cocktail (Sigma - Aldrich). The cells were centrifuged at $13,000 \times g$ for $30 \mathrm{~min}$ at $4^{\circ} \mathrm{C}$ to obtain the supernatant. The cell lysates $(50 \mu \mathrm{g})$ were separated on an $8 \%$ SDS polyacrylamide gel and transferred onto nitrocellulose membranes (Whatman, St. Louis, MO, USA). The membrane was blocked for $2 \mathrm{~h}$ by treatment with Tris-buffered saline containing $0.1 \%$ (v/v) Tween-20 (TBST) and 5\% skim milk, after which antibodies against the following were applied at $4^{\circ} \mathrm{C}$ overnight : Peroxisome proliferator-activated receptors PPAR $\gamma, \mathrm{C} / \mathrm{EBP} \alpha$, Fas, and $\beta$-actin (Cell Signaling Technology, Danvers, USA). The blot was probed by anti-rabbit secondary antibodies (Cell Signaling Technology, Danvers, USA) for $2 \mathrm{~h}$ at $4^{\circ} \mathrm{C}$. The proteins were detected with SuperSignal ${ }^{\circ}$ West Pico chemiluminescent substrate (Thermo Scientific) using the Amersharm Imager 600 (GE Healthcare Life Sciences, Chicago, IL, USA).

\subsection{Statistical analysis}

Data were expressed as the mean \pm standard deviation (SD). Data were analyzed with SPSS 22.0 software by a Student's t-test and ANOVA (non-parametric) analysis for comparison of two groups, followed by post hoc Tukey's multiple comparison test for more than two groups.

\section{Results}

\subsection{Physiochemical Properties of PCF}

The Chemical composition of PCF is shown in Table 1. The sugar, uronic acid, and sulfate content are $34.9 \%, 18.6 \%$, and $11.4 \%$, respectively. Galactose and glucose are major monosaccharides and a minor amount of mannose, arabinose, fucose, rhamnose and xylose are also present.

Table 1. The structural characterization of PCF.

\begin{tabular}{|c|c|c|c|c|c|c|c|c|c|}
\hline \multirow{2}{*}{$\begin{array}{c}\text { Neutral } \\
\text { sugars(\%) }\end{array}$} & \multirow{2}{*}{$\begin{array}{c}\text { Uronic } \\
\text { Acid (\%) }\end{array}$} & \multirow{2}{*}{$\begin{array}{c}\text { Sulfate } \\
(\%)\end{array}$} & \multicolumn{7}{|c|}{ Monosaccharide composition (\%) } \\
\hline & & & $\mathbf{F u c}$ & Rha & Arabinose & Galactose & Glucose & $\mathbf{M}$ & se \\
\hline $34.9 \pm 0.1$ & $18.6 \pm 0.1$ & $11.4 \pm 0.1$ & $5.69 \pm 0.10$ & $5.12 \pm 0.18$ & $11.30 \pm 0.16$ & $81.08 \pm 0.71$ & $77.45 \pm 1.71$ & $28.48 \pm 0.66$ & $4.49 \pm 0.13$ \\
\hline
\end{tabular}

Values are mean \pm SD of three independent experiments

\subsection{Utilization of PCF by Individual Bacteria}

Culture media containing glucose and galacto-oligosaccharide (GOS) was used as a positive control. PCF was added to culture medium to evaluate the proliferation of probiotics and food-born pathogenic bacteria compared to the positive control. The growth of nine microbial strains in these media was individually confirmed after $24 \mathrm{~h}$ incubation (Table 2). PCF promoted the growth of all probiotic strains, with B. bifidum showing the highest amount of growth. PCF also had enhanced prebiotics effects on $L h$ and $L p$ probiotic strains compared to both the glucose and GOS positive controls. By contrast, the growth of the food born pathogenic bacteria was not promoted by PCF.

Table 2. Growth (OD600) of probiotics and food-born pathogenic bacteria grown in brain heart infusion (BHI) medium supplemented with PCF 


\begin{tabular}{cccc}
\hline \multirow{2}{*}{ Strains } & \multicolumn{3}{c}{ Absorbance of culture (OD600) } \\
\cline { 2 - 4 } & Glucose & GOS & PCF \\
\hline Bifidobacterium bifidum & $1.45 \pm 0.05^{\mathrm{g}^{*}}$ & $1.60 \pm 0.01^{\mathrm{h}}$ & $1.53 \pm 0.01^{\mathrm{h}}$ \\
Bifidobacterium animalis subsp. lactis Bb-12 & $1.26 \pm 0.07^{\mathrm{e}}$ & $1.36 \pm 0.07^{\mathrm{f}}$ & $1.16 \pm 0.05^{\mathrm{d}}$ \\
Lactobacillus rhamnosus LGG & $1.26 \pm 0.05^{\mathrm{e}}$ & $1.38 \pm 0.03^{\mathrm{f}}$ & $1.19 \pm 0.01^{\mathrm{d}}$ \\
Lactobacillus helveticus & $1.18 \pm 0.01^{\mathrm{d}}$ & $1.26 \pm 0.03^{\mathrm{e}}$ & $1.33 \pm 0.01^{\mathrm{f}}$ \\
Lactobacillus plantarum subsp. plantarum & $1.26 \pm 0.01^{\mathrm{e}}$ & $1.15 \pm 0.01^{\mathrm{d}}$ & $1.34 \pm 0.01^{\mathrm{f}}$ \\
Lactobacillus brevis & $1.41 \pm 0.01^{\mathrm{g}}$ & $1.47 \pm 0.01 \mathrm{~g}$ & $1.45 \pm 0.01^{\mathrm{g}}$ \\
Bacillus cereus & $1.04 \pm 0.04^{\mathrm{c}}$ & $0.85 \pm 0.07^{\mathrm{b}}$ & $0.72 \pm 0.05^{\mathrm{a}}$ \\
Escherichia coli & $0.98 \pm 0.04^{\mathrm{c}}$ & $0.92 \pm 0.03^{\mathrm{c}}$ & $0.65 \pm 0.06^{\mathrm{a}}$ \\
Salmonella Typhii & $1.05 \pm 0.06^{\mathrm{c}}$ & $0.77 \pm 0.06^{\mathrm{b}}$ & $0.59 \pm 0.05^{\mathrm{a}}$ \\
\hline
\end{tabular}

Values are mean \pm SD of three independent experiments. Sample means with different lower-case letters for the same index are significantly different at $p<0.05$

\subsection{Effect of Fermentation on Cell Viabiity Count, $p H$, and Acidity of PCF}

PCF fermentation was performed and cell viability count, $\mathrm{pH}$, and acidity observed over time. The changes to cell viability during fermentation is shown in Figure 1. The viable cell counts of $L p$ in PCF supplemented media were 9.26 and $7.39 \log C F U / m L$ at 24 and 48h, respectively. For $L h$, the viability count in PCF supplemented medium was 9.41 and $7.81 \log \mathrm{CFU} / \mathrm{mL}$ at 24 and $48 \mathrm{~h}$, respectively. For fermentation with glucose, the viability count for $L p$ and $L h$ were 9.35 and $9.41 \log C F U / m L$ at $24 \mathrm{~h}$ and were 8.06 and $8.89 \log \mathrm{CFU} / \mathrm{mL}$ at $48 \mathrm{~h}$, respectively.

The changes in $\mathrm{pH}$ and acidity of the PCF fermentation solution are shown in Figure 2 and Figure 3. For both $L p$ and $L h$, in PCF supplemented media, fermentation led to a gradual decrease in $\mathrm{pH}$ and increases in acidity. For these lactic acid bacteria, growth results in lactic acid production which explains the increase in acidity from $0.2 \%$ to 2.0 $\%$ and decrease of the $\mathrm{pH}$ from 6.2 to 3.6 after $48 \mathrm{~h}$ fermentation. Compared to when grown in glucose supplemented media, $L p$ and $L h$ presented a lower $\mathrm{pH}$ profile when grown in PCF supplemented media. For $L p$, the acidity level was similar between the PCF and glucose supplemented medias, with an increase from $0.2 \%$ to $2.0 \%$ over the course of the fermentation. For $L h$, the acidity level was lower after fermentation in PCF supplemented medium compared when compared to that of glucose supplemented medium.

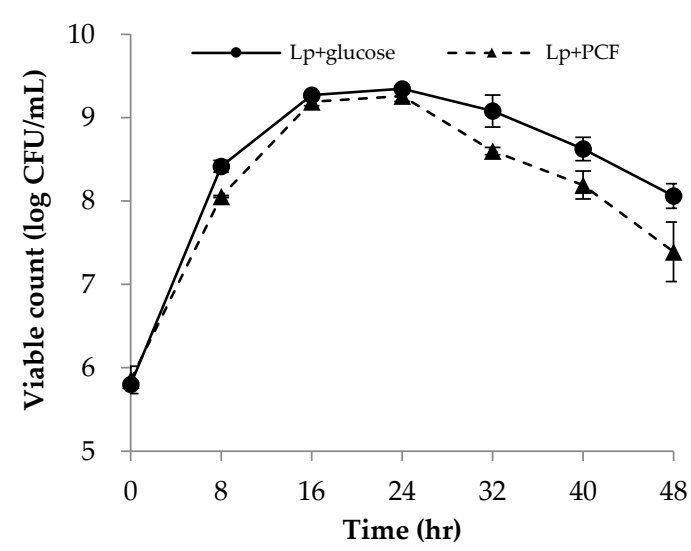

(a)

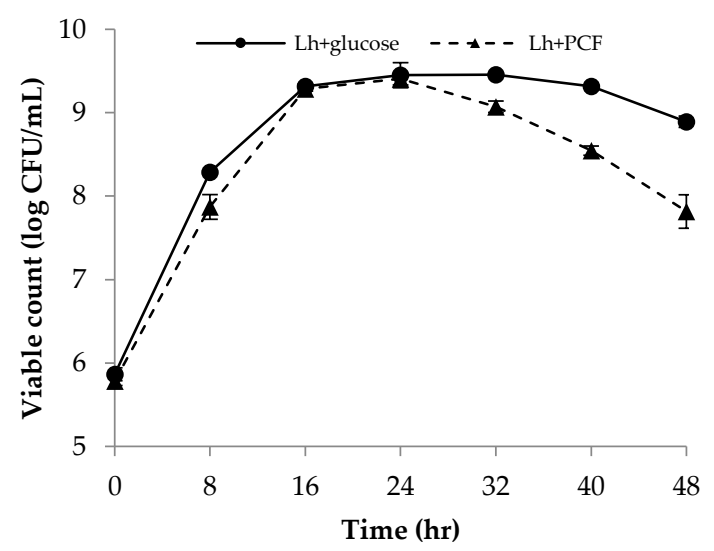

(b)

Figure 1. Changes in cell viability count of $L p(\mathrm{a})$ and $L h(\mathrm{~b})$ with glucose or PCF. Values are expressed as mean \pm SD. 


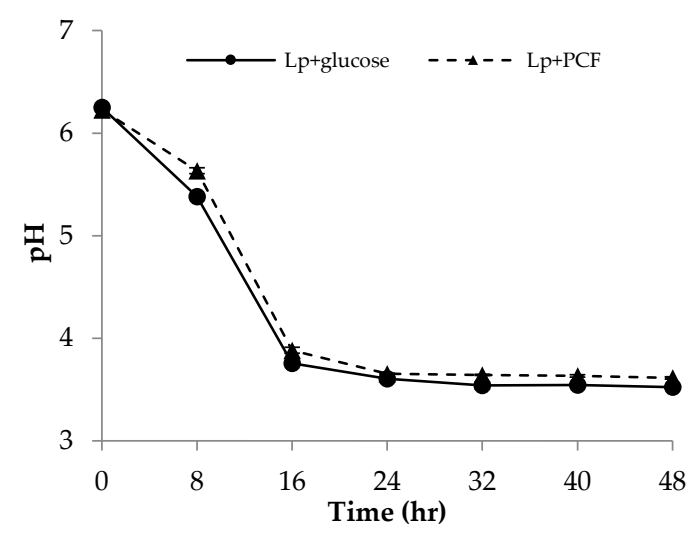

(a)

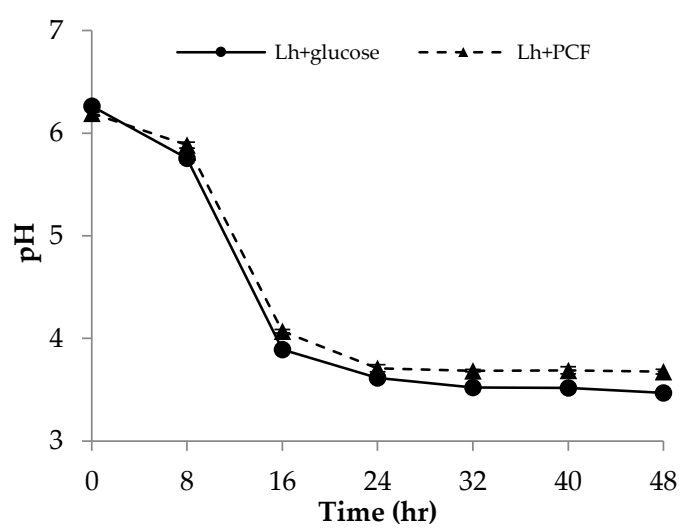

(b)

Figure 2. Changes in cell viability count of $L p(a)$ and $L h(b)$ with glucose or PCF. Values are expressed as mean \pm SD.

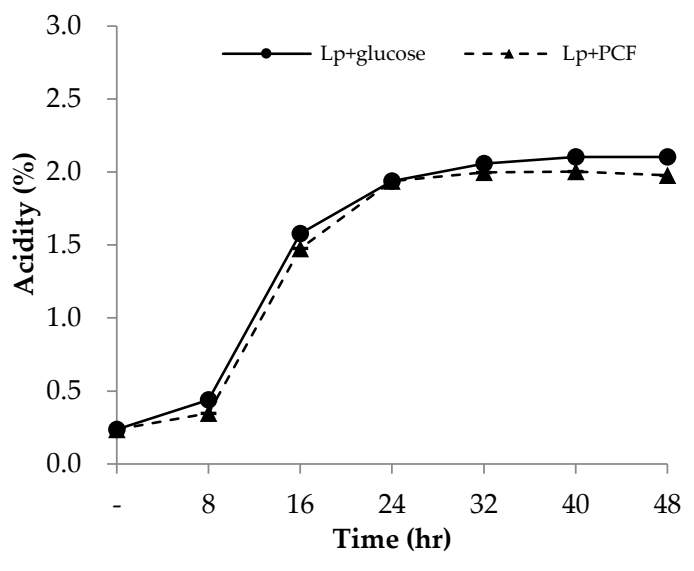

(a)

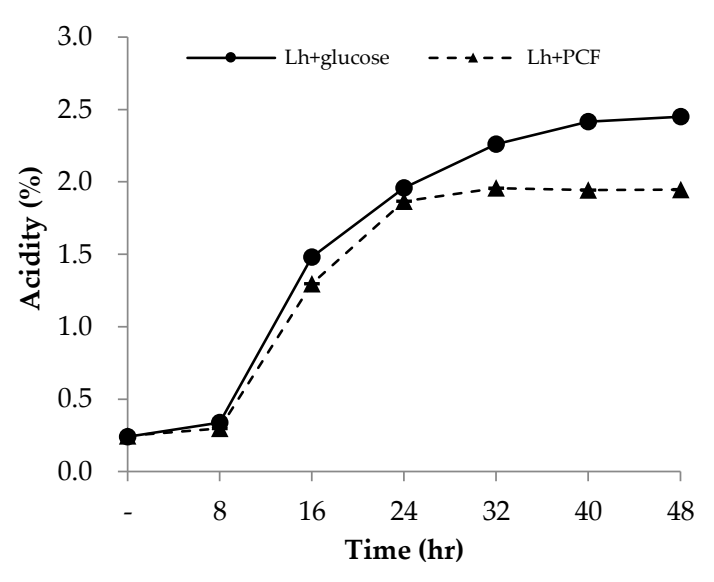

(b)

Figure 3. Changes in acidity of $L p(a)$ and $L h(b)$ with glucose or PCF. Values are expressed as mean \pm SD.

\subsection{Effect of Fermentation on SCFAs, TPC, TFC, and DPPH Activity of PCF}

Table 3 shows SCFAs, TPC, TFC, and DPPH activity in glucose or PCF supplemented media after fermentation by probiotics. When PCF supplemented medium was used, lactic acid levels were lower than for the glucose supplemented medium, whereas acetic acid was higher for the PCF supplemented medium. Butyric acid and propionic acid were not detected in fermentation cultures grown in either medium. Fermentation cultures grown in PCF supplemented medium, showed higher TPC, TFC, and DPPH activity compared to cultures grown in glucose supplemented medium.

\subsection{Inhibition of Lipid Accumulation in 3T3-L1 Cells of PCF}

To evaluate the cytotoxicity of PCF on 3T3-L1 preadipocytes, we performed an MTT assay. As shown in Figure 4(a), PCF $(0.5-6 \mathrm{mg} / \mathrm{mL})$ did not affect cell growth; therefore, 1,2 , and $4 \mathrm{mg} / \mathrm{mL}$ of PCF were used in further studies.

To evaluate the inhibition effect of PCF on adipocyte differentiation, 3T3-L1 cells were cultured in adipocyte differentiation media at different concentrations of PCF. As shown in Figure 4(b), PCF significantly reduced adipocyte differentiation in a dose-dependent manner without inducing cytoxicity. Lipid droplet accumulation in 
3T3-L1 cell treated with 1, 2, and $4 \mathrm{mg} / \mathrm{mL}$ PCF decreased to 13.20, 36.20, and 78.81\%, respectively, relative to untreated cells.

As shown in Figure 4(c), treatment with PCF inhibited PPAR $\gamma, \mathrm{C} / \mathrm{EBP} \alpha$, and Fas protein expression during 3T3-L1 differentiation.

Table 3. SCFAs, TPC, TFC, and DPPH activity of glucose and PCF during fermentation.

\begin{tabular}{|c|c|c|c|c|c|c|c|}
\hline \multirow[b]{2}{*}{ Sample } & \multicolumn{4}{|c|}{ SCFAs (g/kg) } & \multirow{2}{*}{$\begin{array}{c}\text { TPC } \\
\text { (mg GAE/g) }\end{array}$} & \multirow{2}{*}{$\begin{array}{c}\text { TFC } \\
\text { (mg QAE/g) }\end{array}$} & \multirow{2}{*}{$\begin{array}{c}\text { DPPH activity } \\
(\%)\end{array}$} \\
\hline & $\begin{array}{l}\text { Lactic } \\
\text { acid }\end{array}$ & $\begin{array}{l}\text { Acetic } \\
\text { acid }\end{array}$ & $\begin{array}{c}\text { Butyric } \\
\text { acid }\end{array}$ & $\begin{array}{c}\text { Propionic } \\
\text { acid }\end{array}$ & & & \\
\hline$L p+$ glucose & $32.33 \pm 0.27 c$ & $5.42 \pm 0.09^{a}$ & - & - & $37.57 \pm 1.19^{c}$ & $42.97 \pm 1.35^{\mathrm{d}}$ & $10.92 \pm 1.85^{b}$ \\
\hline$L p+\mathrm{PCF}$ & $31.84 \pm 0.92^{c}$ & $5.75 \pm 0.01^{a}$ & - & - & $48.14 \pm 0.26^{\mathrm{d}}$ & $67.72 \pm 2.35^{f}$ & $80.35 \pm 1.90 \mathrm{~g}$ \\
\hline$L h+$ glucose & $35.23 \pm 0.63^{c}$ & $6.09 \pm 0.55^{a}$ & - & - & $37.75 \pm 1.87 c$ & $60.15 \pm 0.54^{\mathrm{f}}$ & $18.12 \pm 4.63^{b}$ \\
\hline$L h+\mathrm{PCF}$ & $30.83 \pm 0.24^{c}$ & $6.89 \pm 0.05^{a}$ & - & - & $58.50 \pm 1.54 \mathrm{e}$ & $81.50 \pm 2.45 \mathrm{~g}$ & $85.92 \pm 6.02 \mathrm{~g}$ \\
\hline
\end{tabular}

Values are mean \pm SD of three independent experiments. -, not detected. Sample means with different lower-case letters for the same index are significantly different at $p<0.05$

(a)

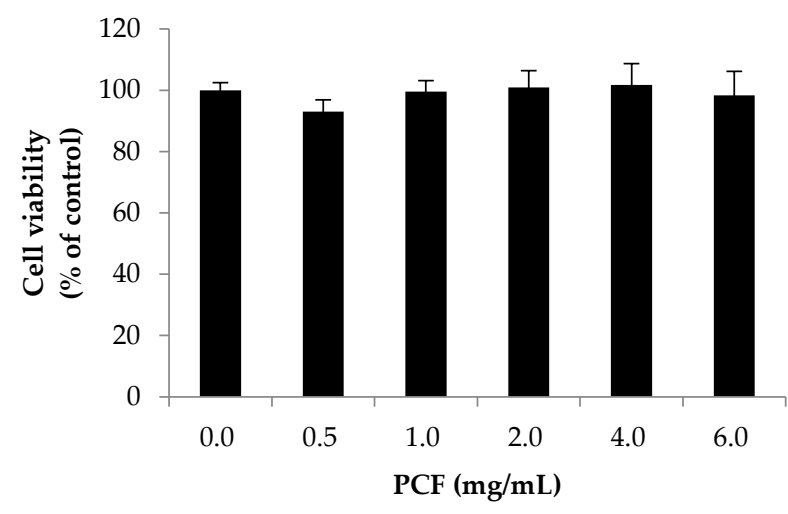

(b)

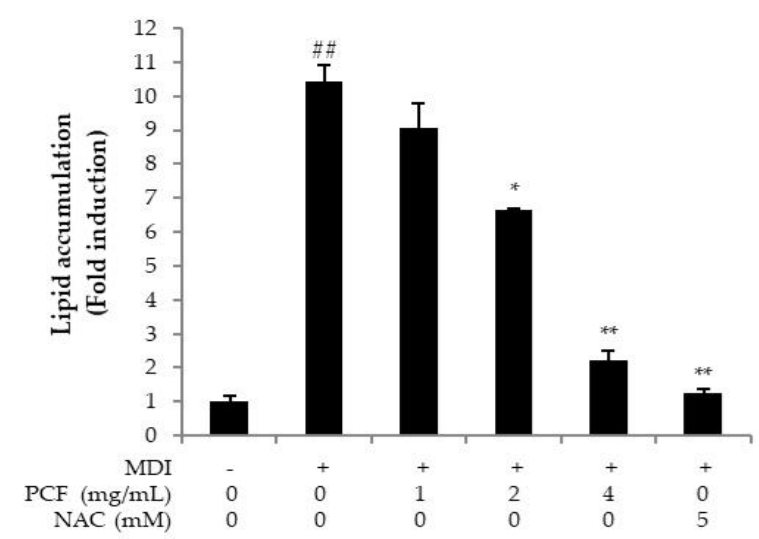

Undifferentiated

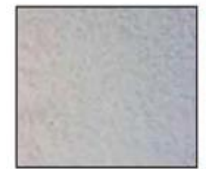

0

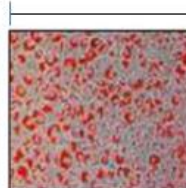

0

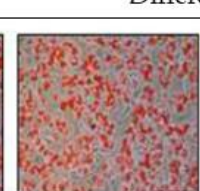
PCF $(\mathrm{mg} / \mathrm{mL})$

Differentiating media (MDI)

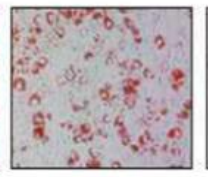

2

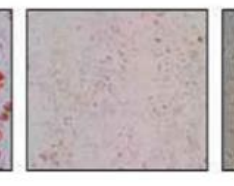

4

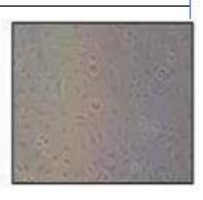

5

NAC (mM) 
(c)

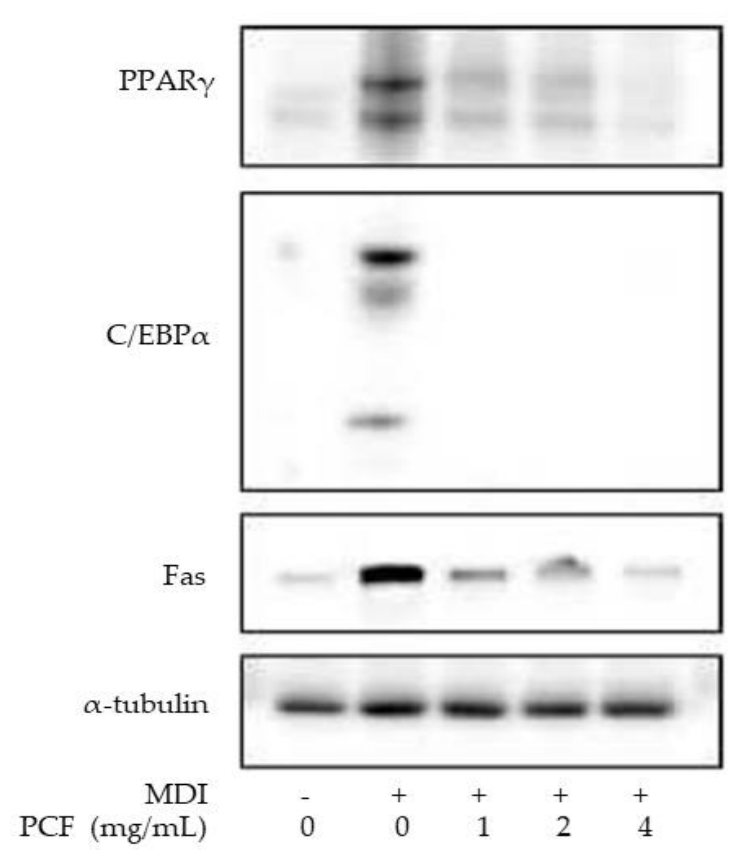

Figure 4. PCF inhibits lipid accumulation in 3T3-L1 cells. (a) Confirmation of cell viability on adipocyte differentiation using MTT assay. (b) Confirmation of the inhibitory effect on adipocyte differentiation using oil red O staining (c) Confirmation of PCF-induced changes in the expression of protein related to adipocyte differentiation using Western blot analysis. Data are representative of more than three separated experiments and are presented as mean $\pm \mathrm{SD}$. Significant differences are noted as ${ }^{*} p<0.05,{ }^{* *} p<0.01$ as compared to differentiated 3T3-L1 cells without PCF treatment. MDI: methylisobutylxanthine, dexamethasone, and insulin, NAC: $N$-Acetyl-cysteine, \#\#p $<0.05$ as compared to normal cells.

\section{Discussion}

The cultivated green algae, C. fragile, contains large amounts of structural sulfated polysaccharides. Partial degradation products of sulfated structural polysaccharides, produced during fermentation by the human gut microbiota, have been shown to have bioactivity [6,14,16-17]. Furthermore, the gut microbiome is well known for its role in regulating obesity and other metabolic disease.

Until now, studies on bioactive compounds from $C$. fragile have been conducted on samples extracted with toxic and expensive organic solvents, such as ethanol, n-hexane, and ethyl acetate. In this study, C. fragile was extracted with water in an environmentally friendly method to yield PCFs. PCFs extracted with water comprise many galactose residues with traces of arabinose, and the presence of sulfate as substituents. In accordance with these results, Yuko et al [13]. reported that sulfated polysaccharides isolated from $C$. fragile were mainly composed of galactose, arabinose, and glucose. Therefore, our results indicate that PCFs belongs to the group of galactan/arabinan (or arabinogalactan).

To evaluate the growth effect of PCF on probiotics, PCF was used as the single carbon source. PCF was able to promote growth of all the probiotic bacteria strains used in this study, while there was no increase in growth of pathogenic bacteria. PCF enhanced the growth of $L p$ and $L h$ to a greater extent than GOS. These results are consistent with a previous report that sulfated galactan can promote the proliferation of lactic acid bacteria [31]. Therefore, fermentation involving of $L p$ and $L h$ with PCF as a substrate was further studied.

The fermentation of PCF with $L p$ and $L h$ resulted in an increase in acidity and a decrease in $\mathrm{pH}$ of the culture medium. When PCF was employed as carbon source, $L p$ and Lh showed a larger decrease in $\mathrm{pH}$ and increase in in acidity compare to when glucose was used as a carbon source. Gupta et al. [32], reported that low pH and accumulation of 
acids during fermentation can decrease growth rate. PCF fermented with probiotics showed the highest viable cell count at $24 \mathrm{~h}$ of fermentation, following which the viable cell count decreased. An inflection point was identified at $24 \mathrm{~h}$ of fermentation in PCF supplemented medium and a sigmoidal curve was observed that correlated with a decrease in the substrate and adaptation of the cells to the second carbohydrate. Compared with the glucose supplemented medium, the growth and cell viability of $L p$ and $L h$ fermented in PCF supplemented medium was similar up to $24 \mathrm{~h}$, but then lowered up until $48 \mathrm{~h}$.

The prebiotic potential of polysaccharides and SCFAs from algae has mainly been studied $[7,33,34]$. There is a scope to determine the prebiotic potential of other phytochemical components, such as polyphenols and carotenoids [35]. Fermentation via lactic acid bacteria may convert various phytochemicals to more bioactive aglycone forms. Ye et al. [36] reported that lactic acid bacteria fermentation significantly increased the level of TPC in vegetables. After fermentation with PCF as a carbon source, the main SCFA was lactate, and acetate level was higher than when glucose was used as a carbon source. SCFAs reduce the number of food-born pathogenic bacteria by acidifying the intestinal $\mathrm{pH}$. TPC, TFC, and DPPH activity after fermentation with PCF as carbon source were higher than for glucose as control. Fermentation disrupts marine algal cell wall resulting in increased polyphenol content in the fermented samples. Therefore, it could be possible to utilize PCF, not only as a prebiotic material, but also as a bioactive material for health promotion by increasing antioxidant activity during fermentation.

Everard et al. [37] reported that prebiotics improve glucose homeostasis and leptin sensitivity; furthermore, enteroendocrine cell activity is improved by modulating specific gut microbiota in obesity and diabetes. In this study, PCF reduced the amount of oil red $\mathrm{O}$ staining compared to control 3T3-L1 cell in dose-dependent manner and blocked expression of PPAR $\gamma, \mathrm{C} / \mathrm{EBP} \alpha$, and Fas during 3T3-L1 differentiation.

In conclusion, these results suggest that PCF promotes the growth of specific beneficial microbial populations with a concomitant decrease in pathogenic microbes. Furthermore, TPC, TFC, and DPPH activity after fermentation with PCF as carbon source were higher cpmpared to glucose as a carbon source. Finally, PCF inhibited adipocyte differentiation by inducing differentiation-related factors during the transformation of 3T3-L1 preadipocytes into adipocytes. Therefore, we suggest that PCF may be used as a prebiotic material with anti-obesity effect on human health.

Funding: This research was funded by the Ministry of Small and Medium-sized Enterprises (SMEs) and Startups (MSS), Korea under the "Regional Specialized Industry Development Plus Program (R\&D, S3005783)" supervised by the Korea Institute for Advancement of Technology (KIAT)

Author Contributions: Conceptualization, S.O., S.K., K.J., P.T.N.A., S.Y., and B.A.; methodology, S.O., P.T.N.A., S.Y., and B.A.; validation, S.O., S.Y., and B.A.; formal analysis, S.O., P.T.N.A., S.Y., and B.A.; investigation, S.O., S.K., P.T.N.A., S.Y., and B.A.; resources, S.O., S.K., P.T.N.A., S.Y., and B.A.; data curation, S.O., P.T.N.A., S.Y., and B.A.; writing-original draft preparation, S.O., and P.T.N.A.; writing-review and editing, S.O., S.Y., and B.A.; supervision, S.Y., and B.A.; project administration, S.O. All authors have read and agreed to the published version of the manuscript.

Conflicts of Interest: The authors declare no conflict of interest.

\section{References}

1. Perez, M.J.; Falque, E.; Dominguez, H. Antimicrobial Action of Compounds from Marine Seaweed. Mar. Drugs 2016, 14, 52.

2. Su, J.; Guo, K.; Huang, M.; Liu, Y.; Zhang, J.; Sun, L.; Li, D.; Pang, K.L.; Wang, G.; Chen, L. Fucoxanthin, a Marine Xanthophyll Isolated From Conticribra weissflogii ND-8: Preventive Anti-Inflammatory Effect in a Mouse Model of Sepsis. Front. Pharmacol. 2019, 10, 906. 
3. Yayeh, T.; Im, E.J.; Kwon, T.H.; Roh, S.S.; Kim, S.; Kim, J.H.; Hong, S.B.; Cho, J.Y.; Park, N.H.; Rhee, M.H. Hemeoxygenase 1 partly mediates the anti-inflammatory effect of dieckol in lipopolysaccharide stimulated murine macrophages. Int. Immunopharmacol. 2014, 22, 51-58.

4. Khalifa, S.A.M.; Elias, N.; Farag, M.A.; Chen, L.; Saeed, A.; Hegazy, M.F.; Moustafa, M.S.; Abd El-Wahed, A.; Al-Mousawi, S.M.; Musharraf, S.G. Marine Natural Products: A Source of Novel Anticancer Drugs. Mar. Drugs 2019, 17, 491.

5. Monmai, C.; Rod-in, W.; Jang, A-y.; Lee, S-m.; Jung, S-K.; You, S.; Park, W.J. Immune-enhancing effects of anionic macromolecules extracted from Codium fragile coupled with arachidonic acid in RAW264.7 cells. PLoS ONE 2020, 15(10).

6. Wells, M. L.; Potin, P.; Craigie, J. S.; Raven, J. A.; Merchant, S. S.; Helliwell, K. E.; Brawley, S. H. Algae as nutritional and functional food sources: Revisiting our understanding. Journal of Applied Phycology 2017, 29, 949-982.

7. O' Sullivan, L.; Murphy, B.; McLoughlin, P.; Duggan, P.; Lawlor, P.G.; Hughes, H.; Gardiner, G.E. Prebiotics from marine macroalgae for human and animal health applications. Mar. Drugs 2010, 8, 2038-2064.

8. Rose, D.J.; Keshavarzian, A.; Patterson, J.A.; Venkatachalam, M.; Gillevet, P.; Hamaker, B.R. Starch-entrapped microspheres extend in vitro fecal fermentation, increase butyrate production, and influence microbiota pattern. Mol. Nutr. Food Res. 2009, 53, S121-S130.

9. Timm, D.A.; Stewart, M.L.; Hospattankar, A.; Slavin, J.L. Wheat dextrin, psyllium, and inulin produce distinct fermentation patterns, gas volumes, and short-chain fatty acid profiles in vitro. J. Med. Food 2010, 13, 961-966.

10. Belenguer, A.; Duncan, S.H.; Calder, A.G.; Holtrop, G.; Louis, P.; Lobley, G.E.; Flint, H.J. Two routes of metabolic cross-feeding between Bifidobacterium adolescentis and butyrate-producing anaerobes from the human gut. Appl. Environ. Microbiol. 2006, 72, 3593-3599.

11. Macfarlane, G.T.; Macfarlane, S. Bacteria, colonic fermentation, and gastrointestinal health. J. AOAC Int. 2012, $95,50-60$.

12. Ríos-Covián, D.; Ruas-Madiedo, P.; Margolles, A.; Gueimonde, M.; de los Reyes-Gavilán, C.G.; Salazar, N. Intestinal short chain fatty acids and their link with diet and human health. Front. Microbiol. 2016, 7, 185.

13. Ohta, Y.; Lee, J.B.; Hayashi, K.; Hayashi, T. Isolation of sulfated galactan from Codium fragile and its antiviral effect. Biol. Pharm. Bull. 2009, 32, 892-898.

14. Cherry, P.; Yadav, S.; Strain, C.R.; Allsopp, P.J.; McSorley, E.M.; Ross, R.P.; Stanton, C. Prebiotics from seaweeds: An ocean of opportunity? Mar. Drugs 2019, 17, 327.

15. Jiao, G.; Yu, G.; Zhang, J.; Ewart, H.S. Chemical structures and bioactivities of sulfated polysaccharides from marine algae. Mar. Drugs 2011, 9, 196-223.

16. Yang, Y.; Park, J.; You, S.G.; Hong, S. Immuno-stimulatory effects of sulfated polysaccharides isolated from Codium fragile in olive flounder, Paralichthys olivaceus. Fish Shellfish. Immunol. 2019, 87, 609-614.

17. Park, S.H.; Kim, J.L.; Jeong, S.; Kim, B.R.; Na, Y.J.; Jo, M.J.; Yun, H.K.; Jeong, Y.A.; Kim, D.Y.; Kim, B.G. Codium fragile F2 sensitize colorectal cancer cells to TRAIL-induced apoptosis via c-FLIP ubiquitination. Biochem. Biophys. Res. Commun. 2019, 508, 1-8.

18. Seca, A.M.L.; Pinto, D.C.G.A. Overview of the antihypertensive and anti-obesity effects of secondary metabolites from seaweeds. Mar. Drugs 2018, 16, 237.

19. Roohinejad, S.; Koubaa, M.; Barba, F.J.; Saljoughian, S.; Amid, M.; Greiner, R. Application of seaweeds to develop new food products with enhanced shelf-life, quality and health-related beneficial properties. Food Res. Int. 2017, 99, $1066-1083$.

20. Wang , H.-M.D.; Li, X.-C.; Lee, D.-J.; Chang, J.-S. Potential biomedical applications of marine algae. Bioresour. Technol. 2017, 244, 1407-1415.

21. You, L.; Gong, Y.; Li, L.; Hu, X.; Brennan, C.; Kulikouskaya, V. Beneficial effects of three brown seaweed polysaccharides on gut microbiota and their structural characteristics: An overview. Int. J. Food Sci. Technol. 2020, 55, 1199-1206

22. Dubois, M.; K. A. Gilles.; J. K. Hamilton.; P. A. Rebers.; F. Smith. Colorimetric method for determination of sugars and related substances. Anal. Chem. 1956, 28: 350-356.

23. Cesaretti, M.; E. Luppi.; F. Maccari.; N. Volpi. A 96-well assay for uronic acid carbazole reaction. Carbohydr. Polym. 2003, 54: 59-61.

24. Dodgson, K.; R. G. Price. A note on the determination of the ester sulphate content of sulphated polysaccharides. Biochem. J. 1962, 84: 106-110.

25. Pharm, T.N.A.; Le, B.; Yang, S.H.; Anticancer activity of the potential Pyropia yezoensis galactan fractionated in human prostate cancer cells. 2020, 26(1): 63-70.

26. Zhang, G.; D. A. Mills.; D. E. Block. Development of chemically defined media supporting high-cell-density growth of lactococci, enterococci, and streptococci. Appl. Environ. Microbiol. 2009, 75: 1080-1087.

27. Singleton, V.L.; Orthofer, R.; Lamuela-Raventós, R.M. Analysis of total phenols and other oxidation substrates and antioxidants by means of folin-ciocalteu reagent. In Methods Enzymol; Elsevier: Amsterdam, The Netherlands, 1999, 299 : 152-178.

28. Chang, C.-C.; Yang, M.-H.; Wen, H.-M.; Chern, J.-C. Estimation of total flavonoid content in propolis by two complementary colorimetric methods. J. Food Drug Anal. 2002, 10, 178-182.

29. Ko M. S.; Lee H. J.; Kang M. J. Antioxidant activities and whitening effects of extracts from Hippophae rhamnoides L. J East Asian Soc Diet Life. 2012, 22(6): 812-817.

30. Lee, J. A.; Cho, Y. R.; Hong, S. S.; Ahn, E. K. Anti-obesity activity of Saringosterol isolated from Sagassum muticum (Yendo) fensholt extract in 3T30L1 cells. Phytother. Res. 2017, 31(11): 1694-1701.

31. Hwang, H. J.; S. Y. Lee.; S. M. Kim.; S. B. Lee. Fermentation of seaweed sugars by Lactobacillus species and the potential of seaweed as a biomass feedstock. Biotechnol. Bioprocess Eng. 2011, 16: 1231-1239. 
32. Gupta, S.; Abu-Ghannam, N.; Scannell, A.G.M. Growth and kinetics of Lactobacillus plantarum in the fermentation of edible Irish brown seaweeds. Food Bioprod Process 2011, 89, 346-355.

33. De Jesus Raposo, M.F.; de Morais, A.M.; de Morais, R.M. Emergent sources of prebiotics: Seaweeds and microalgae. Mar. Drugs 2016, 14, 27.

34. Zaporozhets, T.S.; Besednova, N.N.; Kuznetsova, T.A.; Zvyagintseva, T.N.; Makarenkova, I.D.; Kryzhanovsky, S.P.; Melnikov, V.G. The prebiotic potential of polysaccharides and extracts of seaweeds. Russ. J. Mar. Biol. 2014, 40, 1-9.

35. Gibson, G.R.; Hutkins, R.; Sanders, M.E.; Prescott, S.L.; Reimer, R.A.; Salminen, S.J.; Scott, K.; Stanton, C.; Swanson, K.S.; Cani, P.D.; et al. Expert consensus document: The International Scientific Association for Probiotics and Prebiotics (ISAPP) consensus statement on the definition and scope of prebiotics. Nat. Rev. Gastroenterol. Hepatol. 2017, 14, 491-502.

36. Ye, J.-H.; Huang, L.-Y.; Terefe, N.S.; Augustin, M.A. Fermentation-based biotransformation of glucosinolates, phenolics and sugars in retorted broccoli puree by lactic acid bacteria. Food Chem. 2019, 286, 616-623.

37. Everard, A.; Lazarevic, V.; Derrien, M.; Girard, M.; Muccioli, G.M.; Neyrinck, A.M.; Possemiers, S.; Van Holle, A.; François, P.; de Vos,W.M.; et al. Responses of gut microbiota and glucose and lipid metabolism to prebiotics in genetic obese and diet-induced leptin-resistant mice. Diabetes 2011, 60, 2775-2786. 